\title{
Correction to: Genome constellations of rotavirus A isolated from avian species in Brazil, 2008-2015
}

\author{
Laila A. R. Beserra ${ }^{1} \cdot$ Carla M. Barbosa $^{2} \cdot$ Mikael Berg $^{3} \cdot$ Paulo E. Brandão $^{1} \cdot$ Rodrigo M. Soares $^{1} \cdot$ Fabio Gregori $^{1}$ \\ Published online: 4 December 2020 \\ (C) Sociedade Brasileira de Microbiologia 2020
}

\section{Correction to: Brazilian Journal of Microbiology https://orcid.org/10.1007/s42770-020-00259-4}

The funding information in the original article is incomplete. The correct funding information is:

This work was supported by the São Paulo Research Foundation (FAPESP) - Grant 2014/13531-7, Brazilian Government, by the Coordenação de Aperfeiçoamento de Pessoal de Nível Superior-Brasil (CAPES)—Finance Code PROEX - Grant 1841/2016, National Council for Scientific and Technological Development (CNPq) - Grant 307253/ 2017-1, and by Swedish Research Council—Project No. 2013-6772.

Publisher's note Springer Nature remains neutral with regard to jurisdictional claims in published maps and institutional affiliations.

The online version of the original article can be found at https://oi.org/ $10.1007 / \mathrm{s} 42770-020-00259-4$

Laila A. R. Beserra

laila_andreia@hotmail.com

1 Department of Preventive Veterinary Medicine and Animal Health, School of Veterinary Medicine, University of São Paulo, Av. Prof. Dr. Orlando Marques de Paiva, 87, São Paulo, SP CEP 05508-270, Brazil

2 Institute of Biomedical Sciences, University of São Paulo, Av. Prof. Dr. Prof. Lineu Prestes, 1374, São Paulo, SP CEP 05508 900, Brazil

3 Department of Biomedical Sciences and Veterinary Public Health, Swedish University of Agricultural Sciences (SLU), BVF, Virologi, Box 7028, 75007 Uppsala, Sweden 